\title{
Infoway calls for e-prescribing proposals
}

$\mathrm{C}$

anada Health Infoway issued a call for proposals for a \$40-million national electronic prescription service called PrescribeIT. The service would connect clinicians and pharmacists so prescriptions could be issued electronically. The aim of the proposals, according to the July 15 call, is to deliver a system operating in at least two provinces or territories by late 2017 .

Federal Health Minister Dr. Jane Philpott told a drug policy summit in Ottawa on June 22 that she wants Infoway to develop a system capable of "capturing all prescriptions issued by doctors, not just what was dispensed."

Drugs are the second largest health care expenditure in Canada, after hospitals. According to Infoway, an independent, not-for-profit organization funded by the federal government, adverse events and misuse of medication remain problems.

Infoway has already spent nearly $\$ 200$ million on an incomplete system of provincial and territorial drug-information systems designed to capture complete records of patients' medication usage. Infoway says in its 201516 annual report that drug dispensing profiles for $69 \%$ of Canadians are now available for access by authorized clinicians. However, Infoway-financed drug-information systems were available in only Prince Edward Island, Manitoba, Saskatchewan, Alberta and British Columbia, according to a 2014 Harris/Decima survey conducted for Infoway and the Canadian Pharmacists Association (CPhA). In these five provinces, $91 \%$ of the 447 community pharmacists who responded to the survey said they never accessed prescriptions through these systems.

The survey also showed that despite Infoway's investment of at least $\$ 700$ million in interoperable electronic information systems in clinics and hospitals, clinicians almost never sent prescriptions electronically to pharmacists. Infoway acknowledges in its 2016-17 corporate plan that Can-

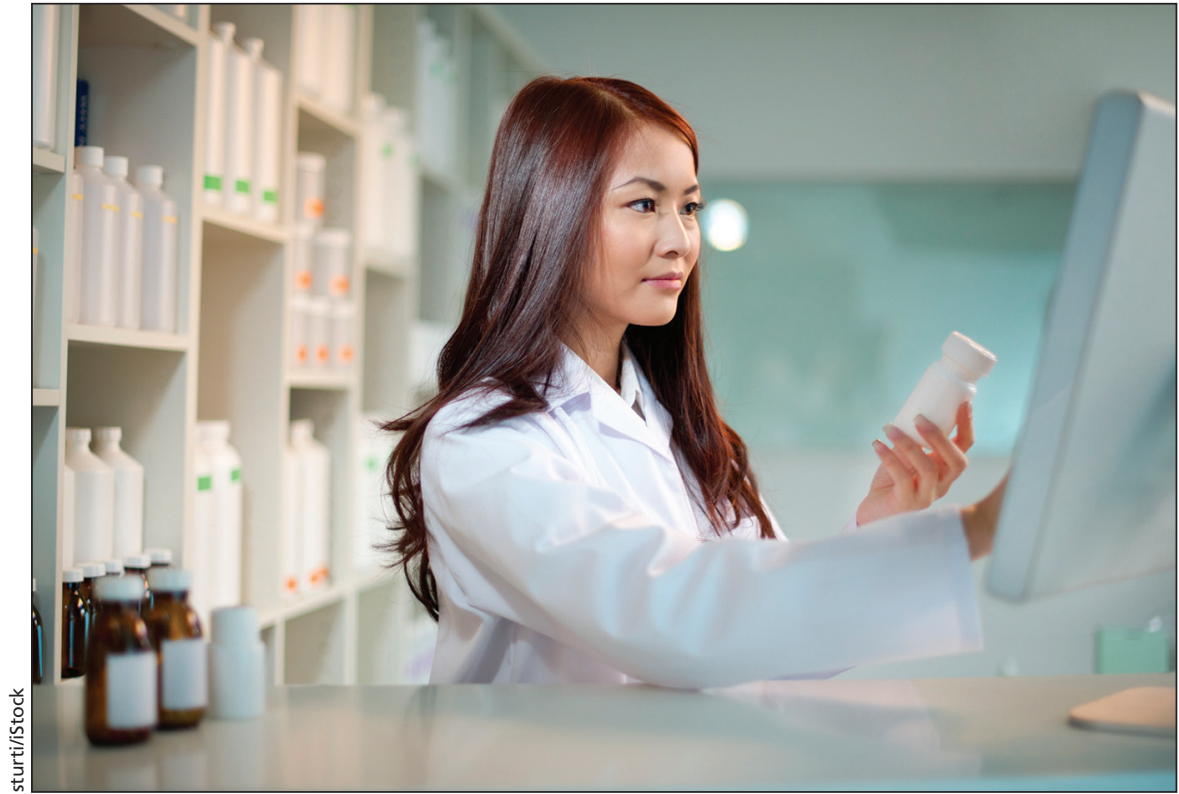

Canada Health Infoway has already spent \$200 million in federal money on a largely incomplete national drug information system.

ada is among the few developed countries without an e-prescribing system.

"When pharmacists were asked to estimate the percentage of total weekly prescriptions received in their pharmacy directly through a physician's eprescribing system, $88 \%$ of respondents said never, with a further $8 \%$ saying less than $10 \%$ of the time," CPhA spokesperson Mark McCondach stated in an email about the 2014 survey results.

Along with the connectivity problem, many doctors still lack electronic medication records. In 2015, only 55\% of Canadian primary care physicians report "being able to use a computerized system to generate medication lists for their patients," according to the Canadian Institute for Health Information.

And even when the technologies are in place, they aren't always used. A 2015 study by Aude Motulsky at the Clinical and Health Informatics Research Group at McGill University in Montréal noted that although Quebec became the first province to implement a "public-driven network for the electronic transmission of prescriptions" in 2011, numerous technological barriers hamper information flow.
The paper in the Journal of the American Medical Informatics Association found, "both physicians and pharmacists did not routinely consult medication histories; this was performed for only a minority of patients."

Respondents to a June 2016 survey conducted for Telus Inc. found only $21 \%$ of Quebecers have refilled prescriptions online; $35 \%$ didn't even know it was possible.

In inviting bids for "an e-prescribing service that will provide for the secure electronic transmission of a prescription from a prescriber to a patient's pharmacy of choice," Michael Green, President and CEO of Infoway, stressed the need for "creative and innovative proposals."

In its request for expressions of interest, Infoway cautions that there are many challenges, mainly because of the large number of connecting systems. "It is expected that at any given time several attaching systems will be unavailable," Infoway cautions in the document. "It is also expected that the operator of the environment will have [developed] or develop disaster recovery plans." 
The $\$ 40$ million for this venture came from the 2016/17 federal budget. Infoway asked for $\$ 180$ million in new "recapitalization," but received a carefully circumscribed $\$ 50$ million over two years for short-term digital health activities in e-prescribing and tele-homecare. Infoway has received $\$ 2.15$ billion since 2001 to cofinance construction of a still incomplete national ehealth infostructure.

Despite the infusion of cash from both federal and provincial governments on Infoway's drug information and clinical interoperability efforts, Infoway now proposes that its longawaited e-prescription system operate on a user-fee basis. - Paul Webster, Toronto, Ont.

CMAJ 2016. DOI:10.1503/cmaj.109-5308 